[Agr. Biol. Ghem., Vol. 25, No. 3, p. 171 175, 1961]

\title{
Studies on Streptomycetes.
}

\author{
Part I. Streptomyces Pulveracenis nov. sp., Producing \\ New Antibiotics Zygomycin A and B \\ By Motoo Shibata, Eiji Higashide, Toshihiko Kanzaki, \\ Hiroichi Yamamoto and Kōiti NaKazawa \\ Research Laboratories, Takeda Pharmaceutical Industries, Ltd., Osaka
}

Received September 15, 1960

\begin{abstract}
Investigation was made on the mycological properties of a strain No. 45449 isolated from a sample of soil collected in Fukuchiyama. Since the antibiotics produced by the strain resembled hydroxymycin and paromomycin, the strain was compared with the hydroxymycinand paromomycin-producing strains, S. paucisporogenes and S. rimosus forma paromomycinus, and as a result the strain No. 45449 was found to be different from the latter two strains. Among known strains, $S$. flavogriseus resembles the present strain, but they are different morphologically and in the kind of the antibiotics they produce. Thus, as the strain No. 45449 was found to be a new strain, it was named $S$. pulveraceus nov. sp. The antibiotics produced by the present strain are physiologically basic substances active against Gram-positive and negative bacteria and acid fast bacteria, and they are considered to belong to the neomycinkanamycin group.
\end{abstract}

\section{INTRODUCTION}

Since the discovery of streptothricin and streptomycin, discovery of a new water-soluble and basic antibiotic having almost the same antibacterial activity as streptomycin but no delayed toxicity as streptothricin has long been desired. Although many basic antibiotics including neomycin were discovered meanwhile, they were not used practically because of their strong toxicity, but Umezawa et al. ${ }^{1)}$ discovered at last in 1957 a new antibiotic, kanamycin, which satisfies the above conditions.

The authors have thereafter isolated a strain No. 45449 from a sample of soil collected in Fukuchiyama and found that it produces an

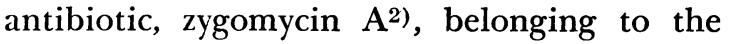

1) H. Umezawa et al., J. Antibiotics Ser. A., 10, 181 (1957).

2) H. Hitomi, S. Horii, T. Yamaguchi and A. Miyake, ibid., under contribution. so-called neomycin-kanamycin group and a new basic antibiotic, zygomycin $\mathrm{B}^{2)}$, which is less toxic than streptomycin and belongs to the streptomycin group. While the present study was carrying out, two antibiotics, hydroxymycin $^{3)}$ and paromomycin ${ }^{4}$, which also seem to belong to the neomycin-kanamycin group and extremely resemble zygomycin A, were reported by other researchers. In the present paper there are reported the mycological properties and antibiotic activity of the strain No. 45449, and results of comparison of the strain with related strains, $S$. paucisporogenes and $S$. rimosus forma paromomycinus, which produce hydroxymycin and paromomycin respectively.

3) G. Hagemann, G. Nominé and L. Pénasse, Ann. Pharm. Franc., 16, 585 (1958)

4) Parke, Davis \& Company, Japanese patent 1958-6649 (1958. 8. 15). 


\section{EXPERIMENTAL}

\section{Mycological Properties}

1) Morphological characteristics

The aerial mycelium generally developes well, and it is powdery and its color is drab-gray or light grayish olive. The sporophore forms spirals and the spore is spherical ellipsoidal, $\quad 0.6 \sim 0.8 \mu \times 0.8 \sim 1.6 \mu$. The spiral, its adhering state and the spore are shown in Fig. 1.

2) Cultural characteristics

The cultural characteristics of the original strain are shown in Table $I$. In order to select a strain with high potency, a mutant was produced by irradiation of the original strain with ultraviolet rays (referred to as yellow mutant). Differing from the original

TABle I. GUltural GharaCteristics of Streptomyces pulveraceus nov. sp. (No. 45449)

Czapek's agar

Glucose Czapek's agar Glycerin Czapek's agar Glucose asparagine agar

Nutrient agar (G) : Glucose nutrient agar

Glycerin nutrient agar

Glucose broth

Starch agar

Egg

Yeast extract agar

Potato plug

Carrot plug

Milk

Nutrient gelatin

Nitrate reduction

Löffer's serum

Gellulose

Calcium malate agar

Tyrosinate agar

Starch hydrolysis
Growth (G): Colorless, later faint brown.

Aerial mycelium (A): Powdery, Light Drab (Rdg.* XLVI, 17" "-b) Light Grayish Olive (Rdg. XLVI, 21" "-b).

Soluble pigment (S): None.

Same as on Czapek's agar.

Same as on Czapek's agar.

(G) : Orange (Rdg. III, 15) Xanthin Orange (Rdg. III, 13-i).

(A): Powdery, Light Grayish Olive.

(S): None, after 3 4 weeks, becoming Ochraceous-Buff (Rdg. XV, 15'-b).
Colorless, folded.
(A): None.
(S) : None.

(G) : Colorless, wrinkled.

(A): None or scant, White to Smoke Gray (Rdg. XLVI, 21" "-d).

(S): Brown.

(G): Wrinkled, Buckthorn Brown (Rdg. XV, 17'-i).

(A): None or scant, white.

(S) : Brown.

(G): Surface growth. (A): Smoke Gray. (S): Brown.

(G) : Colorless Yellow Ocher (Rdg. XV, 17'), penetrating deep into the medium.

(A): Scant, Light Grayish Olive.

(S): None.

(G): Hair Brown (Rdg. XLVI, 17"'"-i). (A): None.

(G): Wrinkled, Chamois (Rdg. XXX, 19"-b) Buckthorn Brown.

(A): Scant, Light Grayish Olive.

(S): Deep brown.

(G): Wrinkled, Pale Orange-Yellow (Rdg. III, 17-f), later Zinc Orange (Rdg. XV, 13'-o).

(A): Powdery, Grayish Olive (Rdg. XLVI, 21" "), Plug is blackend.

(G) : Colorless faint brown.

(A): Powdery, Light Grayish Olive, Plug is slightly brownish.

(G) : Colorless, surface growth.

(S): Brown. Peptonization without coagulation.

(G): Orange. (S): None. Liquefaction.

Reduction, strong.

$\begin{array}{lll}\text { (G) : Colorless. (A): None. (S) : None. } & \end{array}$

No growth.

(G): Yellow, penetrating into the medium.

(A): None or scant, Smoke Gray.

(S): None.

(G) : Colorless faint brown.

(A): Light Grayish Olive. (S): None.

Hydrolysis, enzymatic zone/growth zone $=65 \sim 68 \mathrm{~mm} / 25 \sim 26 \mathrm{~mm}$. 


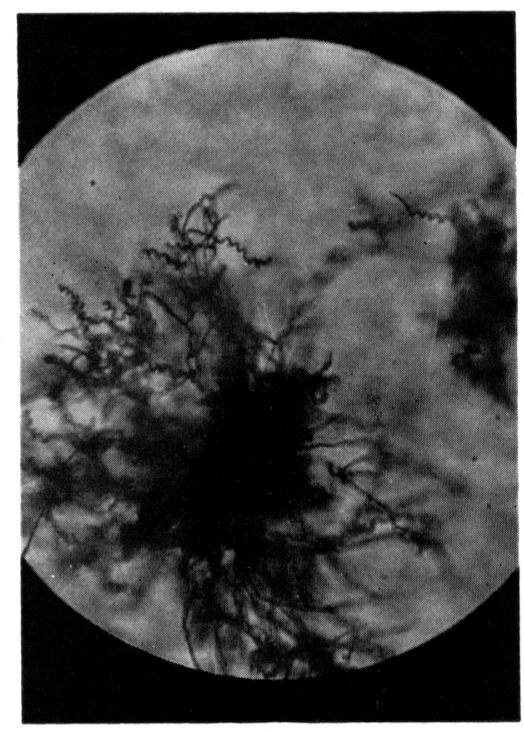

$\times 900$

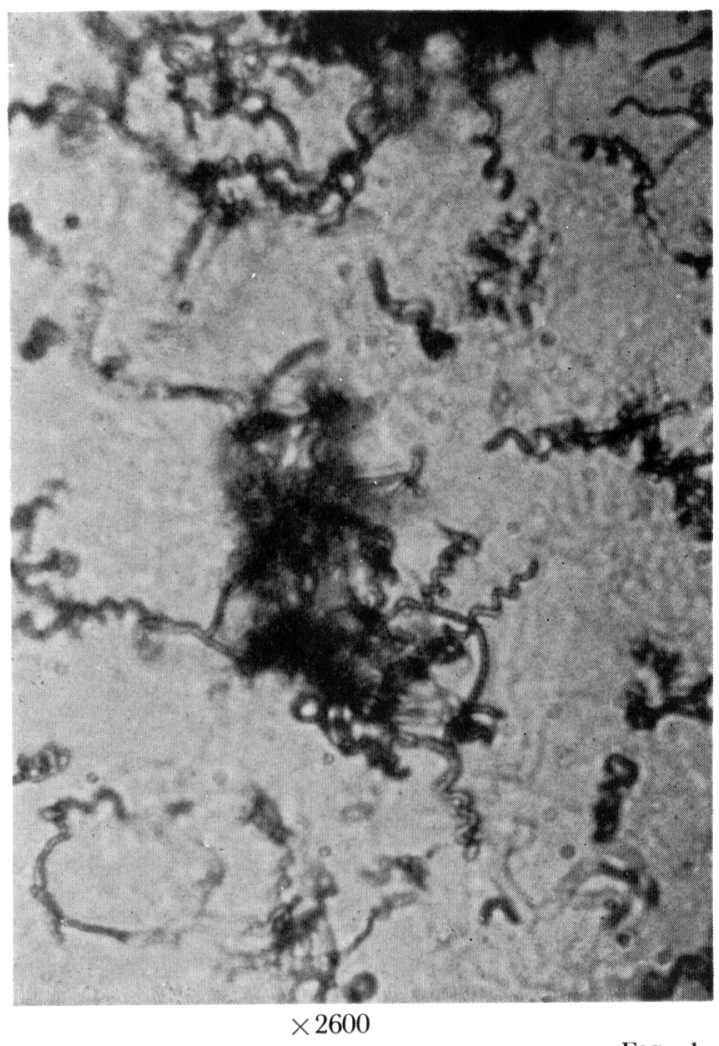

FIG, 1

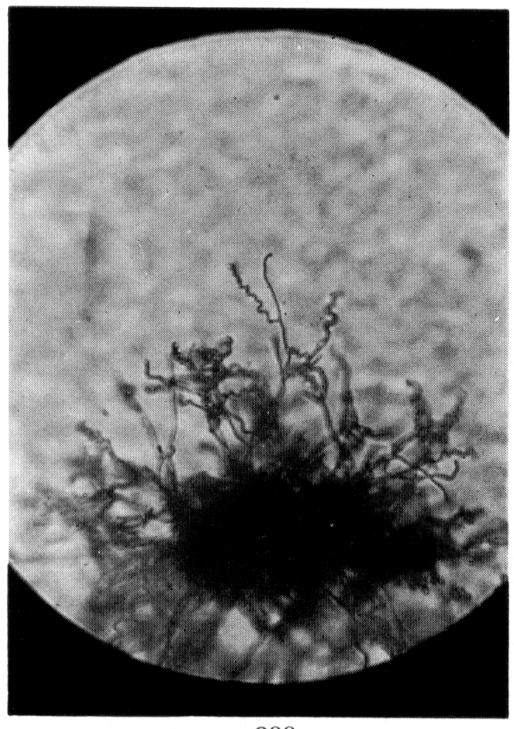

$\times 900$

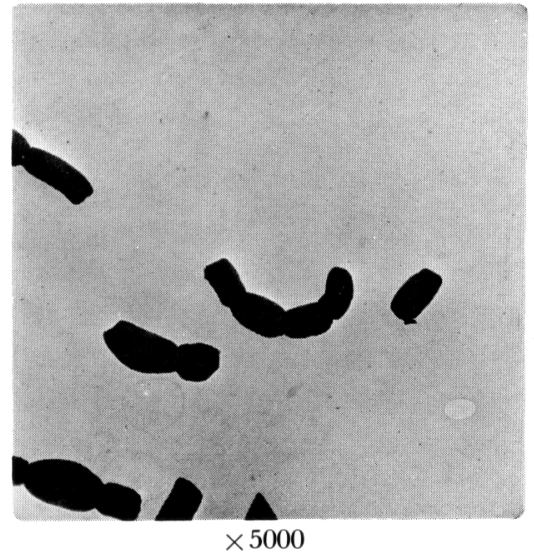




\section{Table II. Gultural Gharacteristics of Yellow-mutant}

Gzapek's agar

Glucose Czapek's agar

Glycerin Czapek's agar

Glucose asparagine agar

Glucose broth

Egg

Potato plug

Carrot plug

Milk
Growth (G): Colorless to Light Ochraceous-Salmon (Rdg. XV, 13'-d).

Aerial mycelium (A): Light Buff (Rdg. XV, 17'-f)

Soluble pigment (S): None.

Same as on Czapek's agar.

(G) : Colorless to Light Ochraceous-Salmon.

(A): Powdery, Buff-Yellow (Rdg. IV, 19-d).

(S) : None.

(G) : Ochraceous-Orange (Rdg. XV, 15').

(A): Pale Yellow-Orange (Rdg. III, 15-f), powdery.

(S): None later becoming faint brown.

(G): Colorless sediment.

(A): None. (S): None.

(G) : Colorless, wrinkled.

(A): None. (S) : None.

(G) : Orange (Rdg. III, 15).

(A): White, Light Buff. Plug is blackend.

(G) : Orange

(A): White, Light Buff. Plug is faint brown.

(G) : Colorless ring.

(S): Yellowish brown. Peptonization without coagulation.
TABLE III. Utilization OF Garbon Sources

\begin{tabular}{|c|c|c|c|c|}
\hline & $\begin{array}{l}\text { S. pulve- } \\
\text { raceus }\end{array}$ & $\begin{array}{l}\text { Yellow- } \\
\text { mutant }\end{array}$ & $\begin{array}{l}\text { S. rimosus } \\
\text { forma par- } \\
\text { omomycinus }\end{array}$ & $\begin{array}{c}\text { S. rimosus } \\
\text { NRRL-2234 }\end{array}$ \\
\hline Arabinose & \pm & - & $-\sim \pm$ & H \\
\hline Rhamnose & Ht & H & - & - \\
\hline Fructose & + & + & H & H \\
\hline D-Galactose & H & H & H & H \\
\hline Saccharose & \pm & \pm & - & - \\
\hline D-Maltose & H & 册 & H & H \\
\hline Lactose & H & $+\sim H$ & $+\sim H t$ & Ht \\
\hline Raffinose & HI & $+\sim \#$ & $\pm \sim+$ & $\pm \sim+$ \\
\hline Inuline & \pm & \pm & - & - \\
\hline D-Mannitol & \pm & \pm & Ht & Ht \\
\hline Sorbitol & + & \pm & H & HH \\
\hline Dulcitol & \pm & \pm & - & - \\
\hline Inositol & \pm & \pm & H & Ht \\
\hline Salicin & $H$ & H & - & - \\
\hline $\mathrm{Na}$-acetate & + & + & & \\
\hline $\mathrm{Na}$-citrate & H & + & & \\
\hline Na-succinate & H & + & & \\
\hline Erythritol & \pm & & & \\
\hline D-Mannose & + & & H & H \\
\hline D-Xylose & H & H & $-\sim \pm$ & $-\sim \pm$ \\
\hline Esculin & H & & - & $-\sim \pm$ \\
\hline Dextran & 卅 & & & \\
\hline Control & \pm & \pm & & \\
\hline & tive utilizati & $\begin{array}{r}\text { on : } \\
\\
\\
\\
\\
+ \\
+ \\
\pm \\
-\end{array}$ & $\begin{array}{l}\text { heavy growth } \\
\text { good growth } \\
\text { fair growth } \\
\text { faint growth } \\
\text { no growth }\end{array}$ & \\
\hline
\end{tabular}

strain, the aerial mycelium of the mutant is yellow, but other properties are almost the same as those of the original strain.

3) Utilizability of carbon source

Carbon source utilizability of the strain No. 45449 and yellow mutant was investigated by the method of Pridham et al.5) In this case, the carbon source utilization of the paromomycin producing strains, $s$. rimosus forma paromomycinus and $S$. rimosus, was also referred to.

At present, the report of the properties of the hydroxymycin producing strain $S$. paucisporogenes and the paromomycin producing strain $S$. rimosus forma paromomycinus is very brief, and therefore, it is impossible to compare the strains with the strain No. 45449 in detail. But $S$. paucisporogenes forms no spiral, produces cracks, and does not reduce nitrate, whereas the strain No. 45449 forms spirals, produces no crack, and strongly reduces nitrate, and thus they are different morphologically as well as biochemically. On the other hand, S. rimosus forma paromomycinus forms white aerial mycelia on all the media described, produces cracks on its growth, and does not peptonize milk, while the strain No. 45449 forms drab-gray grayish olive aerial mycelia, produces no crack on its growth, and well peptonizes milk, and in addition the

5) T.G. Pridham and D. Gottlieb, J. Bact., 56, 107 (1948). 
two strains are different in carbon source utilizability as shown in Table III. S. rimosus NRRL-2234, which was reported to resemble $S$. rimosus forma paromomycinus in various properties such as morphological and cultural characteristics and the utilizability of carbon and nitrogen sources, except the utilization of arabinose, was really cultivated and compared with the strain No. 45449, finding that they are different. In addition to the above-mentioned differences, both $S$. paucisporogenes and S. rimosus forma paromo. mycinus produce no antibiotic belonging to the strepto. mycin group such as zygomycin $\mathbf{B}$, and therefore, they are different from the strain No. 45449 in the kind of the antibiotics they produce.

Among known strains, $S$. flavogriseus appears to resemble the strain No. 45449 , but they are different morphologically because it is described that the aerial mycelium of the former is long and straight hyphae producing a few curling tips, while the latter clearly forms spirals. Further, in view of the fact that the strain No. 45449 produces the two new antibiotics (zygomycin A and zygomycin B), it was judged to be a new strain and therefore, named $S$. pulveraceus nov. sp.

TABle IV. ANTibacterial Spectrum of S. pulveraceus nov. sp.

Inhibition zone $(\mathrm{mm})$

\begin{tabular}{|c|c|c|c|c|}
\hline \multirow{2}{*}{ Test organism } & \\
\hline & 3ouillon & agar & Glyc & erin \\
\hline E. coli & 23 & 24 & 14 & 17 \\
\hline P. vulgaris & 20 & 20 & 15 & 19 \\
\hline B. subtilis & 29 & 30 & 22 & 23 \\
\hline Staphy. aureus & 18 & 19 & 15 & 16 \\
\hline B. cereus & 20 & 20 & 15 & 19 \\
\hline Ps. aeruginosa & 0 & 0 & - & - \\
\hline S. marcescens & 21 & 20 & - & - \\
\hline Mycobact. 607 & - & - & 20 & 22 \\
\hline Mycobact. avium & - & - & 17 & 16 \\
\hline $\begin{array}{l}\text { (Streptomycin- } \\
\text { resistant) }\end{array}$ & - & - & 20 & 19 \\
\hline
\end{tabular}

TABle V. Difference OF ANTIBACTERIAL POWER BY pH CHANGES

Test organism

B. Subtilis

Mycobact. avium

(S. M.-resistant)

\begin{tabular}{|c|c|c|c|}
\hline \multicolumn{4}{|c|}{ Inhibition zone $(\mathrm{mm})$} \\
\hline \multicolumn{2}{|c|}{ pH 6.0-plate } & \multicolumn{2}{|c|}{ pH 8.0-plate } \\
\hline 21 & 22 & 25 & 25 \\
\hline 30 & 29 & 37 & 35 \\
\hline
\end{tabular}

\section{Antibiotic Activity}

The antibacterial spectrum of the strain No. 45449 was investigated by the cross-streak method using bouillon agar and glycerin bouillon agar. On the other hand, the strain was grown on agar-discs and the discs were put on plates having $\mathrm{pH}$ of 6.0 and 8.0 and containing B. subtilis and Mycobact. avium (streptomycin resistant), respectively, and incubated at $37^{\circ} \mathrm{C}$ for twenty hours and forty-four hours to investigate the change of the antibiotic activity (inhibition diameter) by the variation of $\mathrm{pH}$. The results are shown in Table IV and V. According to the results the strain No. 45449 widely inhibits the growth of Gram-positive and negative bacteria and acid-fast bacteria, showing the so-called wide spectrum. And since the strain is more active in basic state, it seems to produce physiologically basic substances.

Known physiologically basic antibiotics which are active against Gram-positive and negative bacteria and acid-fast bacteria are the streptomycin, streptothricin, and neomycin groups. As the strain No. 45449 inhibits the growth of stretpomycin-resistant Mycobact. avium, the antibiotics produced by the strain are not considered to belong to the streptomycin group, and since the activity of the strain against $B$. cereus is stronger than streptothricin group producing strains, the antibiotics produced by the strain more resemble neomycin than streptothricin. From the two features mentioned above, the antibiotics produced by the strain No. 45449 seem to belong to the neomycin group.

\section{SUMMARY}

Investigation was made on the mycological properties of a strain No. 45449 which was isolated from a sample of soil collected in Fukuchiyama. As the antibiotics produced by the strain resembled hydroxymycin and paromomycin, the strain was compared with the hydroxymycin and paromomycin-producing strains, i.e. $S$. paucisporogenes and $S$. rimosus forma paromomycinus, and as a result the strain No. 45449 was found to be a new species and therefore, named $S$. pulveraceus nov. sp. From the antibiotic properties of the strain, the antibiotics produced by the strain were assumed to belong to the neomycin-kanamycin group. 
Acknowledgement The authors are grateful to Dr. Kikiti Sato and Dr. Satoru Kuwada for their advice and encouragement. Thanks are also due to Miss Tomiko Fudanoki for her cooperation.

[Agr. Biol. Chem., Vol. 25, No. 3, p. 176 180, 1961]

\title{
Studies on Streptomycetes.
}

\author{
Part II. Difference between Antibiotic No. 45449-A (Zygomycin A) \\ and other Antibiotics Belonging to the Neomycin Group. \\ By Motoo Shibata, Eiji Higashide, Toshihiko Kanzaki, \\ Hiroichi Yamamoto and Kōiti NaKazawa
}

Research Laboratories, Takeda Pharmaceutical Industries, Ltd., Osaka

Received September 14, 1960

\begin{abstract}
Judging from its antibiotic spectrum and chemical properties, antibiotic No. 45449-A was found to be an antibiotic belonging to the neomycin group.

This antibiotic was compared with other antibiotics belonging to the neomycin group by the following three methods.

First, comparison of the antibiotic spectrum of No. 45449-A with those of ncomycin, kanamycin hydroxymycin and paromomycin indicated that the former is different from the latter. Secondly, test for cross resistance using St. pulveraceus and St. fradiae as test microorganism showed that No. 45445-A is distinguishable from neomycin and kanamycin. Thirdly, investigation of diffusion assay ratios by the method of Fischer et al. also presumed No. 45449-A to be a new antibiotic differing from neomycin and kanamycin.
\end{abstract}

\section{INTRODUCTION}

As reported in the previous paper1), the antibiotic No. 45449-A (referred to as 45449 hereinafter) produced by Streptomyces pulveraceus nov. sp. ${ }^{1)}$ is a basic substance and has antibiotic activity against Gram positive and negative bacteria, acid fast bacteria, and protozoa as seen from its antibiotic spectrum. The antibiotic shows cross resistance with neomycin but not with penicillin, streptomycin,

1) M. Shibata, E. Higashide, T. Kanzaki, H. Yamamoto and K. Nakazawa, This Journal, 25, 171 (1961). tetracycline, and chloromycetin ${ }^{2}$ ). From this property and from the fact that the antibiotic is optically active (dextrorotatory) and is extracted from the culture broth in the same manner as streptomycin and neomycin ${ }^{3)}$, it was found to belong to the neomycin group.

$\mathrm{Up}$ to now the identity of an antibiotic with similar known antibiotics has been discussed from their antibiotic spectrum, sum-

\footnotetext{
2) T. Araki, Y. Oka and K. Tsuchiya, Annual Reports of the Taked Research Laboratory, 19, 131 (1960).

3) H. Hitomi, S. Horii, T. Yamaguchi and A. Miyake, J. Antibiotics
} in press. 